\title{
The Clinical Pharmacology of Vancomycin in Seriously Ill Preterm Infants
}

\author{
MICHAEL D. REED, ROBERT M. KLIEGMAN, JOEL S. WEINER, MARIAN HUANG, \\ TOYOKO S. YAMASHITA, AND JEFFREY L. BLUMER \\ Department of Pediatrics, Divisions of Pediatric Pharmacology and Critical Care and Neonatology, Rainbow \\ Babies and Childrens Hospital; and Departments of Pediatrics and Pharmacology, Case Western Reserve
}

University School of Medicine, Cleveland, Ohio 44106

\begin{abstract}
The first dose and steady state pharmacokinetics of vancomycin were studied in 16 seriously ill preterm infants ( $\leqq 34$ wk gestational age) with documented Staphylococcus epidermidis infections. One infant was dropped from the study due to peripheral flushing occurring during administration of the first dose. Individual vancomycin doses ranged from 9.8 to $17.8 \mathrm{mg} / \mathrm{kg}$ and were infused intravenously over $15-37 \mathrm{~min}$. Fifteen infants were studied after the first dose of vancomycin, whereas only 12 of these 15 were able to be studied under steady state conditions. Vancomycin half-life, steady-state volume of distribution, and body clearance averaged $6.0 \mathrm{~h}, 0.53$ liter/ $\mathrm{kg}$, and $1.22 \mathrm{ml} / \mathrm{min}$ after the first dose and only slight differences were observed in these parameter estimates under steady state conditions. However, substantial accumulation of vancomycin in serum was observed with multiple dosing. Complete 8-h urine collections were possible in 12 of 15 premature infants after the first dose of vancomycin. Overall, $44.6 \%$ of the dose was recovered in the urine with a corresponding vancomycin renal $\mathrm{Cl}_{\mathrm{R}}$ averaging $0.88 \mathrm{ml} / \mathrm{min}$. Vancomycin body $\mathrm{Cl}$ correlated directly with renal $\mathrm{Cl}_{\mathrm{R}}(r=0.88, p<0.001)$ and body weight $(r=0.8$, $p<0.001$ ). Vancomycin pharmacokinetic parameter estimates Vdss and $\mathrm{Cl}$ correlated directly with body weight, surface area, and postconceptional age. No significant relationships were observed between these parameter estimates and gestational age or postnatal age. Fourteen of 15 infants were treated successfully for their underlying infectious process. These data support the use of lower doses of vancomycin than previously recommended for the treatment of preterm infants. (Pediatr Res 22: 360-363, 1987)
\end{abstract}

\section{Abbreviations}

AUC, area under the serum concentration time curve $t_{1 / 2}$, half-life

$\mathrm{Cl}$, body clearance

Vdss, steady state volume of distribution

$\mathrm{Cl}_{\mathrm{R}}$, renal clearance

AUMC, area under the moment curve

$\mathrm{T}$, infusion duration

Received February 9, 1987; accepted April 27, 1987

Correspondence and reprint requests Jeffrey L. Blumer, Ph.D., M.D., Division of Pediatric Pharmacology and Critical Care, Rainbow Babies and Childrens Hospital, 2101 Adelbert Road, Cleveland, $\mathrm{OH} 44106$.

Portions of this work were presented at the Society for Pediatric Research, Washington DC, May 1986 (Pediatr Res 20:204A, 1986), III World Conference on Clinical Pharmacology and Therapeutics, Stockholm, Sweden, July 1986, and the 26th Interscience Conference on Antimicrobial Agents and Chemotherapy, New Orleans, September 1986 (abstr 607).
Nosocomially acquired bacterial infections remain an important cause of morbidity and mortality among infants admitted to neonatal intensive care units (1). The coagulase-negative staphylococci have become increasingly prominent nosocomial pathogens, and are often associated with life-threatening infections (2-4). Battisti et al. (5) have reported that Staphylococcus epidermidis has replaced the group B streptococci as the pathogen most frequently isolated from blood cultures in neonatal intensive care units. Other investigators and recent reviews have reported similar findings $(6,7)$.

The increasing incidence of infections caused by $\beta$-lactam resistant coagulase-negative staphylococci has necessitated the more frequent use of vancomycin. Despite the drug's widespread clinical use (8), limited data are available describing the clinical pharmacology of vancomycin in newborn infants (9-13). Current vancomycin dosage recommendations for newborn infants are derived primarily from single dose evaluations performed in full-term and older infants (9). More recent multidose studies suggest that lower doses than originally proposed should be used in the treatment of seriously ill preterm infants $(11-14)$. Despite these published evaluations, a paucity of paired first dose steadystate vancomycin pharmacokinetic data in the very low birth weight infant (i.e. $<1500 \mathrm{~g}$ ) exists. The purpose of the present study was to describe the first dose and combined steady-state pharmacokinetics of vancomycin in critically ill prematurely born infants with a documented infection due to $S$. epidermidis.

\section{METHODS}

Infants $\leqq 38$ wk gestational age consecutively admitted to the newborn intensive care unit of Rainbow Babies and Childrens Hospital with a suspected or documented infection caused by $S$. epidermidis were eligible for enrollment into this study. Gestational age was estimated by the maternal menstrual history and by physical examination according to the method of Dubowitz et al. (15). Prior to the initiation of antibiotic therapy, a parental history was obtained, a complete physical examination performed, and blood was obtained for the determination of serum electrolytes, creatinine, urea nitrogen, calcium, phosphorous, alkaline phosphatase, alanine aminotransferase, total and direct bilirubin, total protein, albumin, and complete blood count with differential and platelet count. Urine was sent for urinalysis. Routine clinical laboratory determinations of blood and urine were performed at least twice weekly during the study period. Specimens for bacterial and fungal culture were obtained from available sites including blood, urine, and cerebrospinal fluid. Laboratory determinations were performed by the clinical laboratories of the University Hospitals of Cleveland.

All infants with a presumed infection were begun on an aminoglycoside in combination with a $\beta$-lactam antibiotic await- 
ing culture results. Infants from whom $S$. epidermidis was isolated from two blood cultures had their initial antibiotic regimen changed to vancomycin and were enrolled. This study was approved by the Institutional Review Board of the University Hospitals of Cleveland and informed, written consent was obtained from a parent or guardian of each infant.

Drug administration and sample collection. Vancomycin (Vancocin, Eli Lilly \& Co., Indianapolis, IN) was administered intravenously over $30 \mathrm{~min}$. The vancomycin dose $(\mathrm{mg} / \mathrm{kg})$ and dosing interval were selected by each patient's attending physician based on previously published guidelines $(7,8)$. The first dose and steady state study dose of vancomycin were administered via an auto syringe by a research nurse.

Venous blood samples $(\leqq 0.5 \mathrm{ml})$ for the determination of vancomycin in serum were obtained at $0,30,45,60,120,240$, 360 , and $480 \mathrm{~min}$ after the beginning of the infusion and were repeated after the patient had received a minimum of 3 days of uninterrupted therapy. Blood was collected in sterile glass tubes, allowed to clot, and was centrifuged to separate the clot from the serum. Before administration of the first dose of vancomycin, a urine sample was obtained; thereafter, urine was obtained as aliquots from $0-2,2-4$, and $4-8 \mathrm{~h}$ after drug administration. Urine sample volumes were measured and recorded and a $1-\mathrm{ml}$ sample was saved. Serum and urine samples were frozen at $-70^{\circ}$ $\mathrm{C}$ until analyzed. All samples were analyzed within 7 days of collection.

Vancomycin concentrations in serum and urine were determined by fluorescence polarization immunoassay (TDX, Abbott Laboratories, North Chicago, IL) (16). The assay limit of detection was $0.5 \mu \mathrm{g} / \mathrm{ml}$. The between day coefficients of variation were $5.7 \%$ at $35 \mu \mathrm{g} / \mathrm{ml}$ vancomycin and $6.8 \%$ at $7 \mu \mathrm{g} / \mathrm{ml}$.

Pharmacokinetic analysis. Model-independent methods were used to describe the biodisposition of vancomycin (17). Serum vancomycin concentrations for each patient were plotted against time on a semilogarithmic scale. AUC was obtained by using the linear trapezoidal rule up to the final measured concentration and extrapolated to infinity following the first dose and to the dosing interval $\tau$, during steady state conditions. The elimination $t_{1 / 2}$ was determined using the terminal portion of the serum concentration time curve. Vancomycin body $\mathrm{Cl}$ was determined using the formula dose $/ \mathrm{AUC}_{0}{ }^{\infty}$ following the first dose and dose/ $\mathrm{AUC}_{0}{ }^{r}$ during steady state. The Vdss after the first dose was determined using the following equation:

$$
\mathrm{Vdss}=\frac{\text { dose } \cdot \mathrm{AUMC}}{\mathrm{AUC}}-\frac{\text { dose } \cdot \mathrm{T}}{\mathrm{AUC} \cdot 2}
$$

Determination of $\mathrm{Vdss}$ at steady state was calculated using the superposition method (18). The $\mathrm{Cl}_{\mathrm{R}}$ of vancomycin for each patient was calculated as $\mathrm{Cl}_{\mathrm{R}}=\mathrm{A}_{0}{ }^{\infty} / \mathrm{AUC}_{0}{ }^{\infty}$ where $\mathrm{A}$ is the cumulative amount of drug excreted (19). Statistical evaluations were performed using the paired and unpaired Student's $t$ test and regression analysis.

\section{RESULTS}

Demographic and clinical data. A total of 16 seriously ill preterm infants was enrolled into this study. One infant who experienced peripheral flushing $\sim 10 \mathrm{~min}$ into the infusion of the first vancomycin dose was withdrawn from the study by his parents. This infant continued on vancomycin therapy without ill effect. The characteristics of the remaining 15 study patients are shown in Table 1. Infants ranged in gestational age from 25$34 \mathrm{wk}$, post conceptual age from 27-36.5 wk, and postnatal age from 7-43 days. The dose of vancomycin ranged from 9.8 to $17.8 \mathrm{mg} / \mathrm{kg}$ per dose; one infant received vancomycin on a q 6 $h$ dosage regimen whereas the remaining 14 infants received the drug q $8 \mathrm{~h}$. All 15 infants were studied after the first vancomycin dose, 12 of these 15 were able to be studied under steady-state conditions.
In addition to prematurity, 12 of the study infants had respiratory distress syndrome as their primary underlying disease; two had necrotizing enterocolitis and one child was born to a drugaddicted mother. All infants had $S$. epidermidis sepsis. Although one infant had a suspected concurrent meningitis, cultures of the cerebrospinal fluid were sterile. All infants had central venous catheters in place, were mechanically ventilated, and continued to receive concurrent aminoglycoside therapy. Serum creatinine concentrations prior to instituting vancomycin therapy ranged from $0.4-1.3 \mathrm{mg} / \mathrm{dl}$. All isolates of $S$. epidermidis were sensitive in vitro to $\leqq 4 \mu \mathrm{g} / \mathrm{ml}$ of vancomycin. Fourteen of the 15 infants were treated successfully for their infections with vancomycin. With the exception of the one infant who was withdrawn from the study, no infants experienced any adverse effects that could be directly attributed to vancomycin administration. Although previous investigators have suggested an increased incidence of nephrotoxicity in patients receiving combined aminoglycoside vancomycin therapy (20), we were unable to confirm this finding by repeated serum creatinine determinations and assessment of urine output in our study infants.

Pharmacokinetics. The overall (mean $\pm \mathrm{SD}$ ) vancomycin serum concentration time curve after the first dose and under steady state conditions is shown in Figure 1. End of the infusion peak vancomycin concentrations after the first dose averaged $31.2 \mu \mathrm{g} / \mathrm{ml}$ (range $18.8-62 \mu \mathrm{g} / \mathrm{ml}$ ) increasing to $45 \mu \mathrm{g} / \mathrm{ml}$ (range $24.7-73.3 \mu \mathrm{g} / \mathrm{ml}$ ) at steady state. Steady state serum vancomycin concentrations obtained $30 \mathrm{~min}$ after completion of the drug infusion correlated directly with the dose $(\mathrm{mg} / \mathrm{kg})$ administered $r=0.79(p<0.005)$. Eight-h trough concentrations averaged 9.5 $\mu \mathrm{g} / \mathrm{ml}$ (range $5.1-15.3 \mu \mathrm{g} / \mathrm{ml}$ ) after the first dose and $19.4 \mu \mathrm{g} / \mathrm{ml}$ (range $8.1-38 \mu \mathrm{g} / \mathrm{ml}$ ) at steady state.

First dose and steady state pharmacokinetic parameter estimates for vancomycin are shown in Table 2 . Vancomycin elimination $\mathrm{t}_{1 / 2}, \mathrm{Vdss}$, and body $\mathrm{Cl}$ after the first dose averaged $6 \mathrm{~h}$, $0.53 \mathrm{liter} / \mathrm{kg}$ and $1.22 \mathrm{ml} / \mathrm{min}$, respectively. Only slight statisti-

Table 1. Patient characteristics

\begin{tabular}{lcc}
\hline & Mean $( \pm \mathrm{SD})$ & Range \\
\hline Male/female 4:11 & & \\
Gestational age (wk) & $28.4(2.6)$ & $25-34$ \\
Post conceptional age (wk) & $31.4(3)$ & $27-36.5$ \\
Postnatal age (day) & $20.5(10.4)$ & $7-43$ \\
Body wt $(\mathrm{g})$ & $1068.7(435)$ & $650-2380$ \\
Vancomycin dose $(\mathrm{mg} / \mathrm{kg})$ & $12.6(2.8)$ & $9.8-17.8$ \\
Infusion duration $(\mathrm{min})$ & $28.5(6.6)$ & $15-37$ \\
\hline
\end{tabular}

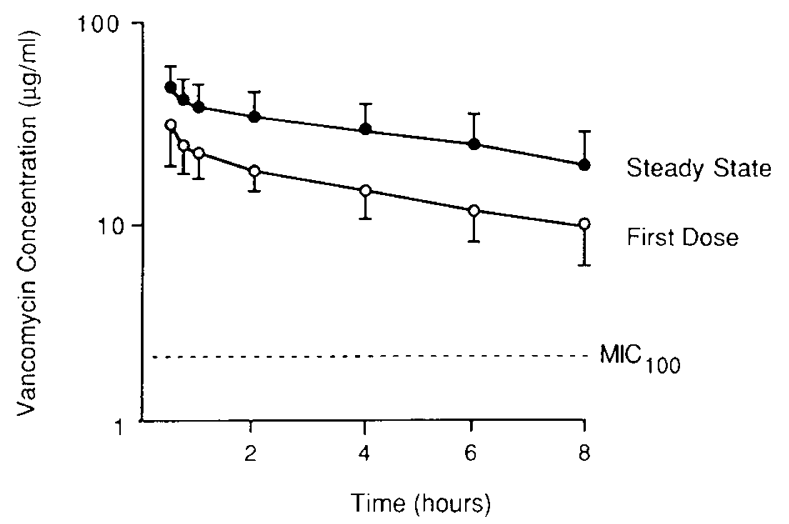

Fig. 1. Overall mean $( \pm \mathrm{SD})$ vancomycin serum concentration time curve after the first dose $(n=15)$ and under steady state $(n=12)$ conditions. All isolates of $S$. epidermidis were sensitive in vitro to $\leqq 4 \mu \mathrm{g}$ / $\mathrm{ml}$ vancomycin. 
cally insignificant differences were observed in these parameter estimates under steady state conditions. The vancomycin dose administered (in $\mathrm{mg} / \mathrm{kg}$ ) correlated directly with steady state AUC (data not shown $r=0.75, p<0.005$ ).

Assessment for relationships that may exist between vancomycin pharmacokinetic parameter estimates and various indices of maturation including gestational age, postconceptual age, postnatal age, body weight, and surface area revealed body weight or surface area as the most significant parameters. Vancomycin Vdss (in liter) correlated directly with patient body weight (in $\mathrm{kg})(r=0.77, p<0.001$ first dose; $r=0.89, p<0.001$ steady state) (Fig. 2), and surface area $(r=0.80, p<0.001$ first dose and $r=0.89, p<0.001$ steady state). A similar relationship was observed between vancomycin body $\mathrm{Cl}$ and patient weight $(r=$ $0.83, p<0.001$ first dose; $r=0.89, p<0.001$ steady state) (Fig. $3)$ and also with surface area $(r=0.84, p<0.001$ first dose and $r=0.89, p<0.001$ steady state). No significant relationships were observed between these vancomycin pharmacokinetic parameter estimates and gestational age or postnatal age. A direct but less significant relationship was observed between postconceptual age and vancomycin Vdss ( $r=0.53, p<0.05$ first dose; $r=0.62, \mathrm{p}<0.05$ steady state $)$ and body $\mathrm{Cl}(r=0.56, p<0.05$ first dose; and $r=0.62, p<0.05$ steady state).

The recovery of vancomycin in the urine after the first dose is shown in Figure 4. Complete timed urine samples were available in 12 of the 15 first dose study patients. Overall, $44.6 \%$ of the dose was recovered unchanged in the urine over the 8-h sampling period. The vancomycin $\mathrm{Cl}_{\mathrm{R}}$ averaged $0.88 \mathrm{ml} / \mathrm{min}$ (Table 2) and correlated directly with vancomycin body $\mathrm{Cl}(r=0.88, p<$ 0.001 ) (Fig. 5). Vancomycin $\mathrm{Cl}_{R}$ correlated directly with the infant's body weight $(r=0.80, p<0.001)$, surface area $(r=0.73$, $p<0.005)$, and postconceptual age $(r=0.60, p<0.05)$, but not with an infant's gestational or postnatal age.

Table 2. First dose and steady state vancomycin pharmacokinetics in premature infants [mean $( \pm S D)]$

\begin{tabular}{lcc}
\hline \multicolumn{1}{c}{ Parameter } & $\begin{array}{c}\text { First dose } \\
(n=15)\end{array}$ & $\begin{array}{c}\text { Steady state } \\
(n=12)\end{array}$ \\
\hline $\mathrm{t}_{1 / 2}(\mathrm{~h})$ & $6.0(2.0)$ & $6.6(2.1)$ \\
$\mathrm{Vdss}($ liter $/ \mathrm{kg})$ & $0.53(0.13)$ & $0.52(0.1)$ \\
$\mathrm{C} 1(\mathrm{ml} / \mathrm{min})$ & $1.22(0.7)$ & $1.16(0.6)$ \\
$\mathrm{C} 1_{\mathrm{R}}(\mathrm{ml} / \mathrm{min})$ & $0.88(0.8)$ & \\
$\mathrm{Cpmax}(\mathrm{mg} / \mathrm{liter})^{*}$ & $31.2(12)$ & $46.4(15)$ \\
$\mathrm{Cpmin}(\mathrm{mg} / \mathrm{liter}) \dagger$ & $9.5(3.5)$ & $19.4(9.2)$ \\
\hline
\end{tabular}

* 30 min postinfusion.

$\uparrow 480$ min postinfusion.

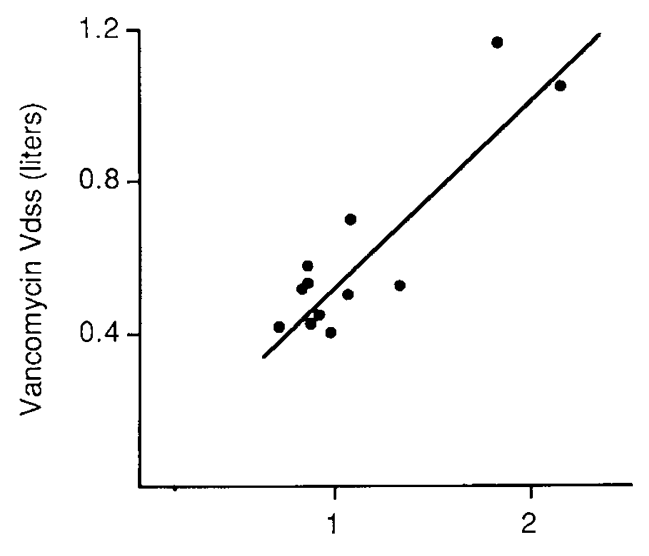

Body weight $(\mathrm{Kg})$

Fig. 2. Relationship between vancomycin Vdss under steady state conditions and body weight $(r=0.89, p<0.001)$.

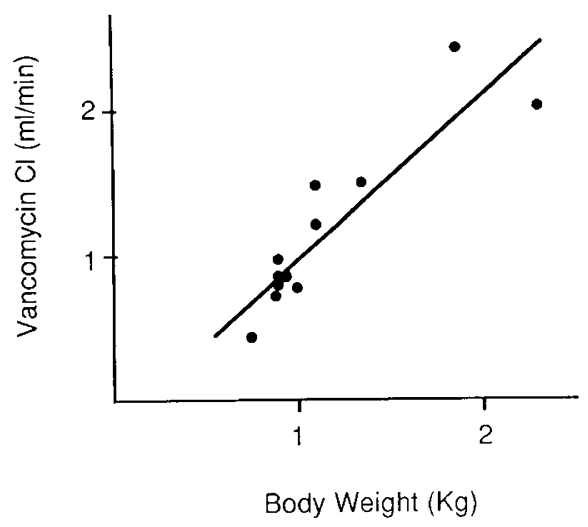

Fig. 3. Relationship between vancomycin body $\mathrm{Cl}$ determined at steady state and infant body weight $(r=0.89, p<0.001)$.

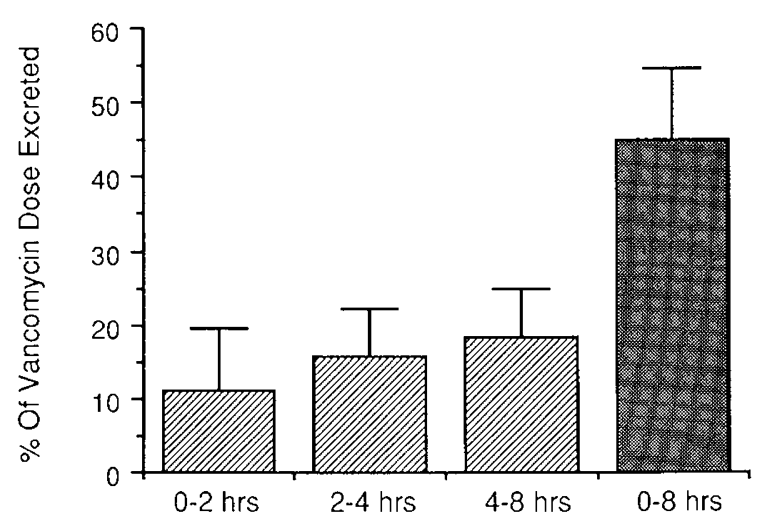

Fig. 4. Urinary recovery of vancomycin after the first dose in 12 premature infants. Each bar represents the mean $( \pm \mathrm{SD})$ for the timed aliquots shown.

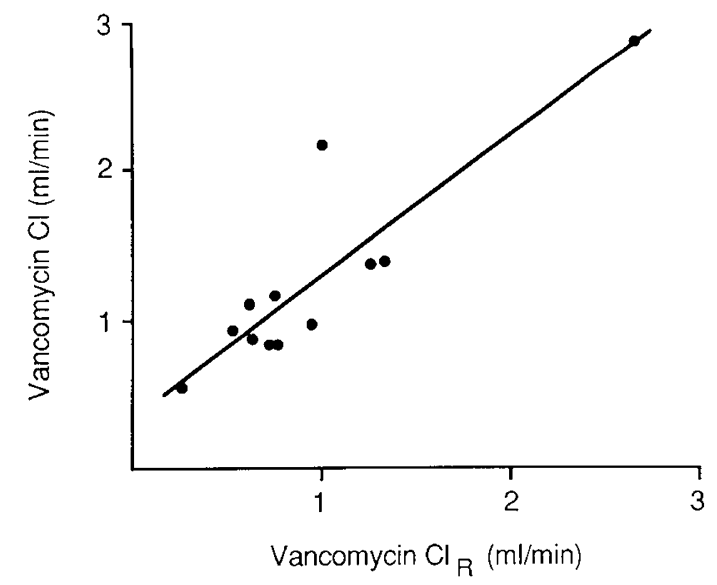

Fig. 5. Relationship between vancomycin body $\mathrm{Cl}$ and $\mathrm{Cl}_{\mathrm{R}}(r=0.88$, $p<0.001$ ).

\section{DISCUSSION}

The biodisposition profile and pharmacokinetics of vancomycin in both pediatric $(9-14)$ and adult patients $(21,22)$ have been described as complex and characterized by a high degree of individual variation. The vancomycin pharmacokinetic data derived in the present study corroborates these findings, particularly for preterm infants. However, the observed variation in our data was not unexpected considering the drug's dependence upon renal function for body elimination $(21,22)$ and the ontogeny of human renal function capacity $(23,24)$ and body water compartmentalization (25). 
Previous investigators describing the biodisposition of vancomycin in premature or full term infants and older children have evaluated data derived from either first dose, steady state, or combined first-dose multidose drug administration (9-13). Initial vancomycin dosage recommendations for infants were extrapolated from data derived from mostly single dose determinations (9). These investigators described a direct relationship between vancomycin body $\mathrm{Cl}$ and chronological age. However, when these earlier vancomycin dosage recommendations based on an infants chronological age are used, substantial accumulation in serum vancomycin concentrations are observed (Fig. 1). For infants more than 8 days of age, 8 -h steady state vancomycin trough concentrations were 2 - to 4 -fold greater than currently recommended for the treatment of staphylococcal infections $(8$, $9,14,21,22)$.

More recent data for vancomycin disposition in premature infants have described highly significant and direct linear relationships between vancomycin body $\mathrm{Cl}$ and postconceptional age $(12,13)$ with limited or no relationship to postnatal age. This finding is most likely related to the observation that postnatal maturation of glomerular filtration rate appears to correlate best with an infant's postconceptional age $(23,24)$. Naqvi et al. (1), Schaible et al. (12), and James et al. (13) have described direct linear relationships between vancomycin body $\mathrm{Cl}$ and postconceptional age with correlation coefficients ranging from $r=0.649$ to $r=0.91$. Similar relationships have been observed for other drugs primarily dependent on renal function for body elimination $(26,27)$. Although in the present study vancomycin body $\mathrm{Cl}$ correlated significantly and directly with postconceptional age (steady state $\mathrm{Cl}, r=0.62, p<0.05$ ), a more significant relationship was observed between $\mathrm{Cl}$ and either body weight (steady state, $r=0.89, p<0.001)$ (Fig. 3) or surface area $(r=0.90, p<$ 0.001 ). A similar relationship between vancomycin body $\mathrm{Cl}$ and body weight can be identified from the data of Gross et al. (10).

This reported variation in the relationship between vancomycin body $\mathrm{Cl}$ and either postconceptional age or body weight surface area may be due to the diversity of infant ages at the time of study. Arant (24) in assessing the ontogeny of renal function described both a high degree of interpatient variation and a relative lack of maturation in the functional capacity of the kidney in infants $\leqq 34 \mathrm{wk}$ postconceptional age. These data wouk suggest that in markedly premature infants, body weight or surface area rather than postconceptional age provided a better reflection of absolute functional renal mass. Additionally, body weight may be a more accurate determinant of maturity than a potentially subjective scoring system.

Over the 8 -h study period, $44.6 \%$ of the first vancomycin dose was recovered in the urine (Fig. 4). The vancomycin $\mathrm{Cl}_{\mathrm{R}}$ averaged $0.88 \mathrm{ml} / \mathrm{min}$ and accounted for $88 \%$ of the overall body Cl (Fig. 5 ), reflecting the near complete dependence of vancomycin elimination on renal function. The vancomycin $\mathrm{Cl}_{\mathrm{R}}$ correlated directly with body weight $(r=0.73, p<0.005)$ and postconceptional age $(r=0.54, p<0.05)$ but not gestational or postnatal age.

The results of the present investigation support the previous findings of a large degree of variation in vancomycin pharmacokinetic data in premature infants (10-13) and documents the substantial accumulation of serum vancomycin concentrations when drug dose is based upon chronologic age (9). James et al. (13) suggest a vancomycin dosing regimen which is graduated based on an infant's postconceptional age or body weight. However, insufficient data are provided to allow a critical evaluation of these recommendations. Using the vancomycin pharmacokinetic parameter estimates derived in the present study to stimu- late immediate postinfusion peaks (using a 30-min infusion duration) between 25 and $35 \mu \mathrm{g} / \mathrm{ml}$, and 12 -h trough concentrations between 5 and $10 \mu \mathrm{g} / \mathrm{ml}$, we recommended a vancomycin dose of $10 \mathrm{mg} / \mathrm{kg}$ administered every $12 \mathrm{~h}$ in infants $\leqq 36$ weeks postconceptional age. Considering the apparent dependence of vancomycin body $\mathrm{Cl}, \mathrm{Cl}_{\mathrm{R}}$, and Vdss on body weight (or surface area) and the observed variation in serum vancomycin concentrations, we would recommend the continued pharmacokinetic monitoring of premature infants receiving uninterrupted vancomycin therapy for greater than 3 days.

\section{REFERENCES}

1. Marks MI. Weich DF 1981 Diagnosis of bacterial infections of the newborn infant. Clin Perinatol 8:537-558

2. Munson DP. Thompson TR. Johnson DE, Rhame FS, VanDrunen N. Ferrieri P 1982 Coagulase-negative staphylococcal septicemia: experience in a newborn intensive care unit. J Pediatr 101:602-605

3. Fleer A, Senders RC, Visser MR, Bijlmer RP. Gerards LJ, Kraaijeveld CA. Verhoef J 1983 Septicemia due to coagulase-negative staphylococci in a neonatal intensive care unit: clinical and bacteriological features and contaminated parenteral fluids as a source of sepsis. Ped Infect Dis 2:426-431

4. Baumgart S. Hall SE. Campos JM. Polin RA 1983 Sepsis with coagulasenegative staphylococci in critically ill newborns. Am J Dis Child 137:461463

5. Battisti O. Mitchison R. Davies PA 1981 Changing blood culture isolates in a referral neonatal intensive care unit. Arch Dis Child 56:775-778

6. Scherer LR. West KW. Weber TR, Kleiman M. Grosfeld JL 1984 Staphylococcus epidermidis sepsis in pediatric patients: clinical and therapeutic considerations. J Pediatr Surg 19:358-36

7. Kumar ML. Jensen HB. Dahms BB 1985 Fatal Staphylococcal epidermidis infections in very low-birth-weight infants with cytomegalovirus infection. Pediatrics 76:110-112

8. McHenry MC, Gavan TL 1983 Vancomycin. Pediatr Clin North Am 30:3147

9. Schaad UB, McCracken GH, Jr. Nelson JD 1980 Clinical pharmacology and efficacy of vancomycin in pediatric patients. J Pediatr 96:119-126

10. Gross JR, Kaplan SL. Kramer WG, Mason EO 1985 Vancomycin pharmacokinetics in premature infants. Pediatr Pharmacol 5:17-22

11. Naqvi SH. Keenan WJ. Reichley RM. Fortune KP 1986 Vancomycin pharmacokinetics in small, seriously ill infants. Am J Dis Child 140:107-1 10

12. Schaible DH. Rocci ML Jr, Alpert GA. Campos JH. Paul MH. Polin RA Plotkin SA 1986 Vancomycin pharmacokinetics in infants: relationships to indices of maturation. Pediatr Infect Dis 5:304-308

13. James A, Koren G, Milliken J. Soldin S. Prober C 1987 Vancomycin pharmacokinctics and dose recommendations for preterm infants. Antimicrob Agents Chemother 31:52-54

14. Alpert G. Campos JM. Harris MC. Preblud SR, Plotkin SA 1984 Vancomycin dosage in pediatrics reconsidered. Am J Dis Child 138:20-22

15. Dubowitz LMS. Dubowitz. V. Goldberg C 1970 Clinical assessment of gestational age in the newborn infant. J Pediatr 77:1-10

16. Filburn BH, Shull UH. Tempera YM. Dick JD 1983 Evaluation of an automated fluorescence polarization immunoassay for vancomycin. Antimicrob Agents Chemother 24:216-220

17. Gilbaldi M, Perrier D 1982 Pharmacokinetics, 2nd ed. Marcel Dekker. New York

18. Bauer L. Gibaldi M 1983 Computation of model-independent pharmacokinetic parameters during multiple dosing. J Pharm Sci 72:978-979

19. Wagner JG 1979 Fundamentals of Clinical Pharmacokinetics. Drug Intelligence Publications. Hamilton. II

20. Odio C. McCracken GH Jr. Nelson JD 1984 Nephrotoxicity associated with vancomycin-aminoglycoside therapy in four children. J Pediatr 105:491493

21. Cheung RPF. DiPiro JT 1986 Vancomycin: an update. Pharmacotherapy $6: 153-169$

22. Matzke GR, Zhanel GG, Guay DRP 1986 Clinical pharmacokinetics of vancomycin. Clin Pharmacokinet 11:257-282

23. Leake RD. Trygstad CW 1977 Glomerular filtration rate during the period of adaptation to extrauterine life. Pediatr Res 11:959-962

24. Arant BS Jr 1978 Developmental patterns of renal functional maturation compared in the human neonate. J Pediatr 92:705-712

25. Friis-Hansen B 1983 Water distribution in the foetus and newborn infant. Acta Pediatr Scand 305(suppl):7-11

26. Kasik JW. Jenkins S, Leuschen MP. Nelson RM Jr 1985 Postconceptional age and gentamicin elimination half-life J Pediatr 106.502-505

27. Reed MD, Kliegman RM. Yamashita TS, Blumer JL 1987 The clinical pharmacology of imipenem and cilistatin in premature infants. Pediatr Res $21: 241 \mathrm{~A}$ 